\title{
As estratégias competitivas e colaborativas e os resultados individuais e coletivos no associativismo rural em Quatro Pontes (PR)*
}

\author{
Mali Teresinha Kunzler** \\ Sergio Bulgacov***
}

\begin{abstract}
Sumário: 1. Introdução; 2. Estratégias competitivas e colaborativas em associações; 3. O associativismo rural; 4. Resultados dos relacionamentos interorganizacionais: individuais e coletivos; 5 . Metodologia; 6. Apresentação e análise dos resultados; 7. Considerações finais.
\end{abstract}

Summary: 1 . Introduction; 2 . Strategies; 3 . The rural associativism; 4. Inter organiza-
tional relationship results: individual and collective; 5. Methodology; 6. Presentation
and analysis of the results; 7. Final considerations.

Palavras-Chave: redes; estratégia competitiva e colaborativa; resultados individuais e coletivos.

KEY WORDs: networks; competitive strategy and collaborative; individual and collective results.

Este trabalho busca compreender de que forma as estratégias de competição e de colaboração existentes nas associações de produtores rurais influenciam os resultados individuais e coletivos obtidos pelos produtores participantes. A metodologia utilizada é de natureza descritiva com abordagem qualitativa em multinível em estudo múltiplo

\footnotetext{
* Artigo recebido em nov. 2009 e aceito em dez. 2010.

** Professora da Universidade Estadual do Oeste do Paraná (Unioeste) de Cascavel e Marechal Cândido Rondon (PR). Mestre em administração pela Universidade Federal do Paraná (UFPR). Endereço: rua Gaspar Martins, 471, CEP: 85940-000 — Quatro Pontes, Paraná, Brasil. E-mails: Marli@dknet.com.br; Marli.kunzler@bol.com.br.

*** Professor da FGV/SP da área de estratégia e análise organizacional. Doutor em administração pela Eaesp/FGV. Mestre em administração pela FEA/USP. Pesquisador bolsista do CNPq. Endereço: rua José Francisco Dalledone, 105, CEP: 82200-164 — Curitiba, Paraná, Brasil. E-mails: Sergio. bulgacov@fgv.br; s.bulgacov@gmail.com.
} 
de casos. Os três casos referem-se à associação de produtores de uvas e vinhos, de produtores orgânicos e uma abordagem integrada de nove associações de linhas. Os níveis de análise referem-se aos associados, às associações e às instituições e empresas envolvidas com as associações. Como instrumento de coleta de dados utilizou-se de entrevistas com uso de roteiro semiestruturado, da observação não participante e da análise documental. Para o tratamento dos dados foi utilizada a análise de conteúdo e para a análise dos dados a tabulação em categorias. O principal resultado deste estudo demonstra como as estratégias de competição e de colaboração existentes nas associações de produtores rurais influenciam os resultados individuais e coletivos obtidos pelos produtores participantes.

Individual and collective results of competitive and collaborative strategies in three rural associations from the region of Quatro Pontes (PR)

This work seeks to comprehend in what manner competitive and collaborative strategies influence the individual and collective results obtained by producers participating in rural producer associations. The methodology used is of a descriptive nature with a multilevel qualitative approach to multiple case studies. The three cases included in the study are an association of grape and wine producers, an association of organic producers, and an integrated approach to nine road line associations. The levels of analysis consist of the associates, the associations, as well as the institutions and businesses involved with the associations. Data was collected using semi-structured script interviews, non-participant observation, and historical document analysis. The data was tabulated into categories and subjected to content analysis. The primary result of this study demonstrates how competitive and collaborative strategies influence individual and collective results obtained by producers participating in rural producer associations.

\section{Introdução}

Promover o desenvolvimento e a sustentabilidade econômica e social local é um desafio para a região oeste do Paraná, que é constituída, em sua grande maioria, de pequenas propriedades rurais onde se destaca a produção agropecuária e agroindustrial. Embora essas atividades sejam alternativas produtivas e contribuam para geração de empregos, renda e impostos, praticadas isoladamente não são suficientes para aumentar a renda dos produtores rurais e de suas famílias em níveis que promovam sua permanência no campo. Nesse contexto, Leismann (2007) chama a atenção para a questão da sustentabilidade econômica das pequenas propriedades agrícolas. Onde o modelo produtivo voltado para commodities é considerado esgotado por muitos. Entretanto, algumas alternativas para esses agricultores devem ser consideradas, visto que as consequências da inviabilização econômica têm impactos sociais relevan- 
tes, como dificuldades de adaptabilidade a outras atividades, a desestruturação do modelo produtivo que foi a base do desenvolvimento da região e os efeitos da migração, que levam, principalmente, ao crescimento desordenado das periferias das cidades.

O associativismo rural tem sido uma alternativa adotada pelos produtores rurais em busca da sustentabilidade, principalmente aos das pequenas propriedades onde, para Schermerhorn Jr. (1975), a cooperação entre organizações é um fenômeno que pode ser descrito como a presença de atividades comuns onde dois ou mais negócios, de alguma maneira independente, trabalham para um objetivo comum e na expectativa de benefícios mútuos.

$\mathrm{Na}$ perspectiva da dependência dos recursos entende-se que nenhuma organização é capaz de gerar todos os recursos de que necessita e que nem toda atividade pode ser realizada somente internamente de maneira isolada e independente (Hall, 2004). Desta forma, as organizações passam a depender de seu ambiente e de outras organizações para obter o acesso aos recursos necessários. As interações de uma organização com seu ambiente ocorrem por meio dos relacionamentos com outras organizações em virtude de que estas são as fontes dos recursos necessários.

Nesse sentido, a interdependência e a ação organizacional reduzem a dependência por recursos individuais e ampliam a dependência dos recursos coletivos. Aldrich (1979) acrescenta que a competição por recursos escassos leva à dependência de algumas organizações em relação a outras. A perspectiva da dependência dos recursos tem como elemento básico a escolha estratégica. A perspectiva da estratégia, por sua vez, considera as ações coletivas como uma das muitas oportunidades estratégicas que podem ser exploradas quando se busca melhorar a posição de uma organização perante seus competidores.

Nesse caso, a atenção é direcionada à necessidade de ajustar as respectivas estratégias entre os parceiros para que o relacionamento contribua positivamente para o alcance dos objetivos de cada uma das partes, bem como à necessidade de aprender a operar em novos mercados domésticos ou externos, ou ainda, diversificar com novas atividades (Child e Faulkner, 1998; Pfeffer e Salancik, 1978; Hall, 2004; Castro, 2007). No ajuste estratégico, para Gerlach (2004) é necessário avaliar formas organizacionais que possam servir como meios de inclusão socioeconômicos para indivíduos e empresas que, individualmente, estão distantes de influenciar ou participar de mercados cada vez mais competitivos e socialmente excludentes.

Nesse sentido, este trabalho busca compreender de que forma as estratégias de competição e de colaboração existentes nas associações de pro- 
dutores rurais influenciam os resultados individuais e coletivos obtidos pelos produtores participantes.

A seguir são apresentadas as categorias que fundamentam a análise dos dados desta pesquisa.

\section{Estratégias competitivas e colaborativas em associações}

Tradicionalmente, as estratégias de competição são indicadas como as principais ações utilizadas pelas organizações na busca da vantagem competitiva (Child e Faulkner, 1998). Entretanto, como visto, diante das incertezas ambientais, as organizações que buscam objetivos em comum podem atuar em conjunto com outras organizações através da utilização de estratégias de colaboração para alcançar objetivos que individualmente seriam impossíveis de serem alcançados (Amato Neto, 2000; Balestrin e Vargas, 2004; Levin e Mcdonald, 2006). Dessa forma, as organizações podem utilizar de estratégias competitivas e colaborativas simultaneamente para gerenciar sua interdependência, diminuir o impacto das mudanças ambientais e, ainda, obter vantagem competitiva. Segundo Child, Faulkner e Tallman (2005), a estratégia colaborativa pode ajudar a melhorar a estratégia competitiva pelo fato de aumentar as qualidades da vantagem competitiva, além de fortalecer a estratégia corporativa, facilitando atingir os propósitos da organização. Segundo os autores, a estratégia colaborativa é a tentativa das organizações de realizar seus objetivos através de cooperação com outras organizações ao invés de competir com elas. Desta forma, uma estratégia colaborativa pode oferecer vantagens significativas para empresas que estão carentes de competências particulares ou recursos, em função de possibilitar, através de ligações com outras empresas, obter habilidades complementares ou bens; acesso mais fácil para novos mercados; oportunidades para sinergia mútua e aprendizado. Os autores destacam, ainda, que na estratégia competitiva há a questão sobre como um empreendimento pode ganhar vantagem sobre seus competidores, existindo duas amplas tradições de pensamento sobre estratégia competitiva. A primeira enfatiza como lucros superiores podem derivar da estrutura do setor, dentro da qual uma empresa está localizada, a partir da busca de estratégias genéricas, liderança de custo, diferenciação ou enfoque - conforme se ajusta às condições do setor, ou o modifica (Porter, 1980). A segunda chama a atenção para a vantagem competitiva, que pode ser ganha com competências únicas da empresa e recursos, os quais combinam entregar produtos de valor e difíceis de imitar ou adquirir 
(Collis, 1996). Segundo Child, Faulkner e Tallman (2005), uma estratégia de colaboração, com uma ou mais empresas, pode ser contrapartida para a busca de vantagem competitiva em ambas as tradições de pensamento sobre estratégia competitiva. A habilidade de manter ambos, a estrutura de uma indústria e a posição da empresa, pode ser aprimorada pela cooperação mesmo com os competidores. Isto pode ser considerado uma aliança defensiva contra empresas dominantes ou para assegurar uma posição específica em um setor, ou ainda, reduzir a oportunidade para novos entrantes.

Casarotto Filho e Pires (2001) acrescentam que uma pequena empresa pode competir com diferenciação de produto associado ou não a um nicho de mercado; liderança de custo, participando como fornecedor de uma grande rede topdown; ou flexibilidade/custo, participando de uma rede de empresas flexíveis. Entretanto, Child, Faulkner e Tallman (2005) ressaltam que a cooperação pode existir com a competição, mas não sem tensões e resultados variáveis. Onde a colaboração é intensa e a competição não o for, haverá fortes pressões para que ocorra a fusão dos parceiros, ou para um adquirir o outro. Onde tanto as condições da competição como a colaboração são fortemente presentes, as tensões entre os parceiros serão aparentes, mas os parceiros estarão preocupados em aprender um com o outro rapidamente. Onde a cooperação e a competição são irrelevantes entre as empresas, a aliança deixará de ser importante por parte de seus dirigentes e possivelmente alcançará resultado limitado e será descartada como uma opção estratégica. Porém, onde forças competitivas entre parceiros são muito altas, mesmo depois de a aliança ter sido estabelecida e a cooperação ainda for baixa, o risco de um parceiro se apropriar da habilidade e conhecimento de outro é alto.

Independente da motivação para sua formação, qualquer aliança requer habilidade na administração da colaboração para gerar retornos aos parceiros envolvidos. A confiança é um componente essencial em cooperação e é amplamente considerada pelos gestores envolvidos em alianças estratégicas (Child, Faulkner e Tallman, 2005). A confiança eleva as possibilidades de resultados coletivos. Segundo Amato Neto (2000), a cooperação em associações empresariais pode viabilizar o atendimento de uma série de necessidades, entre as quais se destacam: combinar competências e utilizar o know-how de outras empresas; dividir ônus de realizar pesquisas tecnológicas, compartilhando o desenvolvimento e o conhecimento adquirido; partilhar riscos e custos de explorar novas oportunidades, através da realização de experiências em conjunto; oferecer uma linha de produtos de qualidade superior e mais diversificada; exercer uma maior pressão sobre o mercado, de modo a aumentar a força competitiva em benefício ao cliente; compartilhar recursos, com destaque aos 
que estão sendo subutilizados; fortalecer o poder de compra; e adquirir mais força para atuar em outros mercados.

Nesse sentido, Levin e McDonald (2006) apresentam a abordagem da vantagem do recurso como uma alternativa ao pensamento econômico neoclássico, pois permite a formação de alianças entre pequenas empresas importantes, mesmo entre competidores. Segundo Levin e McDonalt (2006), a inclusão da abordagem dos recursos compartilhados em rede tem uma visão consistente com a visão baseada em recursos. Como visto, se uma empresa tem um nível baixo de recursos, ela deve buscar uma aliança com outras empresas. E, de posse do recurso, poderá buscar o seu uso de modo mais eficiente que os seus competidores e, assim, obter maior vantagem competitiva. Fechando o ciclo da colaboração e da competição.

Para Levin e McDonald (2006), o conceito de coopetição descreve a cooperação entre empresas competidoras. As alianças entre competidores estão se tornando cada vez mais comuns, uma vez que promovem a competição e mudam o foco da competição de empresa para empresa para de rede para rede. Segundo esses autores, embora o compartilhamento melhore a competitividade de cada empresa, a competitividade ampliada não ocorre à custa do consumidor, pois este frequentemente se beneficia das alianças à medida que essas lhes criam valor, oferecendo produtos e preços melhores. Os autores exemplificam que os fazendeiros de algodão podem juntar-se numa grande produção de algodão a fim de que cada produtor se beneficie e o consumidor também. Entretanto, é importante destacar os princípios fundamentais da aplicação dos conceitos de redes para esse fim, onde se destacam: a interação, o relacionamento, a ajuda mútua, o compartilhamento, a integração e a complementaridade (Cândido, 2001).

\section{0 associativismo rural}

As associações de pequenos agricultores são entidades que agrupam certo número de produtores com interesses comuns, tendo como finalidade resolver os problemas de forma coletiva e com o uso de práticas solidárias (Muenchen, 1996).

Araújo (2003) ressalta que a organização do segmento agropecuário tem como característica típica um grande número de produtores rurais, predominantemente pequenos, distribuídos e distanciados em grandes espaços com pouca organização representativa, de modo que não possuem capacidade suficiente para formar o preço de seus produtos. Esta realidade demons- 
tra a fragilidade do segmento agropecuário, consequência da desorganização, da falta de informação dos produtores, da fragilidade da organização e da coordenação das cadeias produtivas. Nesta condição, o segmento "dentro da porteira" é tomador de preços dos demais segmentos (a montante e a jusante da produção) e, por isso, perde participação no conjunto dos negócios do agronegócio.

Assim, verifica-se que a formação e a participação em associações dinâmicas têm auxiliado empresas e produtores, especialmente micro, de pequeno e médio porte, a ultrapassar as conhecidas barreiras ao crescimento, a produzir eficientemente e a comercializar seus produtos em mercados nacionais e internacionais (Drouvot e Fensterseifer, 2002; Rowley, 1997).

Atenção especial tem sido dispensada às associações em virtude de sua capacidade de captar e veicular demandas sociais de diferentes segmentos, em diversas situações, admitindo-se que, de acordo com o engajamento desses mediadores sociais, os "associados" podem encaminhar suas reivindicações e fortalecer sua ação política (Costa e Ribeiro, 1999).

Ganança (2006) ressalta que o associativismo rural produtivo geralmente tem tido forte apoio do Estado, onde o Programa Nacional de Fortalecimento da Agricultura Familiar (Pronaf) e outros, de empréstimos e incentivos para agricultores geridos por bancos públicos e de fomento, optam por canalizar seus recursos para associações de produtores e agricultores. Como o Ministério da Agricultura, Pecuária e Abastecimento (Mapa), por meio da Secretaria de Desenvolvimento Agropecuário e Cooperativismo (SDC), que conduz uma série de programas que estimulam a organização de associações rurais e cooperativas, com o objetivo de contribuir para a melhoria das condições de vida no meio rural. O Departamento de Cooperativismo e Associativismo (Denacoop, SDC, Mapa) desenvolve projetos em parceria com entidades representativas de associações, instituições de ensino, pesquisa e extensão e organismos internacionais, visando levar ao produtor rural organizado a capacitação tecnológica, a cooperação entre associações e o estímulo à competitividade, o que permite investir no estabelecimento de economias regionais seguras, independentes, autossuficientes e de pequena escala (Brasil, 2008). Para o Mapa, associações de produtores rurais são sociedades formais, criadas com o objetivo de integrar esforços e ações dos agricultores e seus familiares em benefício da melhoria do processo produtivo e da própria comunidade à qual pertencem (Brasil, 2008).

O modelo associativo apoiado pelas entidades públicas resulta em organizações com duplo objetivo: prestação de serviços de promoção humana e social aos moradores da localidade e repasse de recursos oficiais. Desta forma, 
as ações se orientam para os serviços de educação, saúde e modernização da base produtiva (Costa e Ribeiro, 1999). A estratégia de desenvolvimento local representa uma alternativa diante do modelo tradicional de desenvolvimento rural, direcionado pelo paradigma produtivista. Neste sentido, surgem como alternativas "programas de desenvolvimento local centrados na exploração diversificada dos recursos locais, objetivando não mais a produtividade crescente, mas a sustentabilidade da população local" (Carneiro, 1999).

A união dos pequenos produtores em associações torna possível a aquisição de insumos, máquinas e equipamentos com menores preços e melhores prazos de pagamento, bem como reúne esforços em torno de benefícios comuns como o compartilhamento do custo da assistência técnica, tecnologias e capacitação profissional. Desta forma, a atuação por meio das associações permite aos produtores participantes minimizar dificuldades no meio rural, que são iguais ou semelhantes a todos, e propiciar melhor desempenho para competir no mercado (Brasil, 2008).

Segundo Abrantes (2004), a união de pequenos empreendedores, especialmente na área agrícola, apresenta uma série de vantagens como aumento da produtividade, redução dos custos, obtenção de descontos, produção em escala, facilidades na comercialização, melhores preços na compra e venda conjunta, troca de informações e técnicas pelos associados, eliminação do intermediário, redução do risco, aumento do convívio social, fortalecimento da cidadania, resolução de problemas comuns e fortalecimento diante de dificuldades técnicas, econômicas e sociais.

Independente dos objetivos das associações rurais, busca-se nesta forma de organização algum tipo de benefício para seus associados. Neste sentido, associações são instrumentos legais para reivindicar junto ao Estado projetos de desenvolvimento comunitário (Azevedo, 2006).

\section{Resultados dos relacionamentos interorganizacionais: individuais e coletivos}

Segundo Wegner e Dahmer (2004), a problemática da avaliação do desempenho na rede de empresas se dá em função da necessidade de se considerar a existência de um contexto em que a individualidade das empresas convive com a coletividade da rede. Neste caso, não somente as empresas que participam da rede precisam utilizar indicadores para sua avaliação, mas também a própria rede necessita ser avaliada adequadamente, já que as duas dimensões se inter-relacionam e se influenciam mutuamente. Como as organizações utili- 
zam individualmente os relacionamentos para alcançar objetivos estratégicos, seu resultado também pode ser mensurado através do alcance dos objetivos individuais (Parkhe, 1993; Yan e Gray, 1994). Coletivamente, os resultados dos relacionamentos interorganizacionais podem ser avaliados em termos do alcance dos objetivos esperados pelo grupo quando da formação de tais relacionamentos (Geringer e Hebert, 1989).

Bengtsson e Kock (1999) demonstram, como resultante de duas pesquisas, que as empresas podem estar envolvidas em quatro tipos diferentes de relacionamentos horizontais ao mesmo tempo: competição, cooperação, coopetição e coexistência, que conferem às companhias vantagens de diferentes formas. Uma empresa que tem uma posição forte e não precisa de recursos externos do competidor provavelmente se concentrará no relacionamento baseado na competição. A vantagem da competição ocorre em função de forçar as companhias a tomar medidas nem sempre requisitadas pelos clientes a fim de constantemente melhorar seus negócios. Para a empresa que precisa de recursos do competidor e não tem uma posição forte, a cooperação é a melhor opção. A vantagem da cooperação está relacionada com o desenvolvimento, porém a função de cooperação enfatiza mais o acesso a recursos do que a força motora ou a pressão por desenvolvimento. Através da cooperação a companhia ganha competência, mercado, conhecimento, reputação, acesso a outros produtos, e outros recursos de importância para o negócio. Uma empresa com uma posição forte, mas com falta de recursos do competidor deve concentrar-se num relacionamento coopetitivo. Este relacionamento contém tanto cooperação e competição e deve ser considerado como o mais útil, à medida que as companhias de certa forma se ajudam e até certo ponto forçam a outra a se desenvolver. Finalmente, uma empresa numa posição fraca na rede de negócio, comparada com um competidor que não está interessado em cooperação, deve tentar estabelecer um relacionamento contendo coexistência. A vantagem da possibilidade da coexistência vem da oportunidade de desenvolvimento posterior de interações com os clientes. A vantagem vem da ausência de ações agressivas por parte dos competidores, não forçando um ao outro a desenvolver soluções que não sejam as exigidas pelos clientes.

Tsai (2002) investigou a eficácia dos mecanismos de coordenação no compartilhamento de conhecimento em redes intraorganizacionais, que consistem tanto de laços cooperativos quanto de laços competitivos internamente às unidades organizacionais. O resultado da pesquisa demonstra que a estrutura hierárquica formal e centralizada tem um efeito negativo significativo sob o compartilhamento de conhecimento entre as unidades que competem entre si por participação no mercado, mas não entre as unidades que compe- 
tem entre si por outros recursos internos. Desta forma, a centralização reduz o compartilhamento de conhecimento interunidade quando a competição de mercado existe entre as unidades, enquanto a interação social melhora o compartilhamento de conhecimento quando a competição pelo mercado existe entre as unidades. Este resultado sugere que a descentralização e a interação social são particularmente importantes ao encorajar o fluxo de conhecimento entre as unidades organizacionais que competem.

Luo, Slotegraaf e Pan (2006) desenvolveram um estudo concentrado na coopetição, o qual envolveu gerentes de nível médio e altos executivos de empresas de setores de alta tecnologia como biotecnologia, desenvolvimento de software, tecnologia de informação e eletrônicos da China. Os resultados obtidos indicam que a coexistência da cooperação interfuncional e da competição pode criar sinergia que melhora o aprendizado das empresas.

Chien e Peng (2005) pesquisaram a intensidade da competição, da cooperação e da coopetição, mediante a análise dos contratos de licitação de uma rede composta de 13 empresas da indústria de simuladores em Taiwan. O estudo desenvolveu equações de intensidade de competição, cooperação e coopetição para delinear os comportamentos de competição e cooperação na rede. Segundo os autores, os atores competem primeiro e, então, cooperam. Os autores identificaram que a competição e a cooperação coexistem na rede, e que a frequência competitiva assim como a frequência cooperativa variam em diferentes pares.

\section{Metodologia}

O objeto desta investigação são as associações de produtores rurais de Quatro Pontes (PR). As categorias de análise são representadas pelas estratégias de competição e de colaboração da perspectiva de produtos e mercados; dos relacionamentos interorganizacionais; e dos resultados individuais e coletivos obtidos pelos produtores participantes. Os procedimentos metodológicos são de natureza descritiva, explicativa e qualitativa aplicados em estudo múltiplo de casos. A abordagem qualitativa de análise envolveu três tipos de associações de produtores rurais de Quatro Pontes, sendo uma associação de produtores de uvas e vinhos; uma associação de produtores orgânicos; e nove associações de linhas, ${ }^{1}$ o que corresponde a 11 associações participantes em três casos.

\footnotetext{
${ }^{1}$ Associações de linhas são arranjos comunitários que seguem um posicionamento geográfico no território, geralmente uma estrada.
} 
Em relação ao delineamento da pesquisa, no que tange aos níveis e unidades de análise, a pesquisa foi realizada considerando três níveis. O primeiro nível diz respeito aos associados das associações pesquisadas, sendo a unidade de análise os produtores rurais. O segundo nível de análise trata das associações de produtores rurais, sendo as unidades de análise os presidentes das associações de produtores. O terceiro nível são as empresas e entidades envolvidas junto aos produtores e às associações, sendo a unidade de análise os dirigentes dessas entidades, empresas e programas, especificamente, o dirigente da Secretaria de Desenvolvimento Econômico da Prefeitura Municipal de Quatro Pontes (PR), o dirigente da Empresa de Assistência Técnica e Extensão Rural (Emater) local e o dirigente do Projeto de Desenvolvimento da Fruticultura Regional (Profrut) da Emater Toledo. Como instrumento de coleta de dados utilizou-se de entrevistas com uso de roteiro semiestruturado, a observação não participante e a análise documental. A coleta de dados foi realizada com um corte temporal transversal, que considerou o período de dois anos, sendo 2008/09.

Quanto aos três casos estudados, o primeiro grupo é constituído pela associação de produtores de uvas e vinhos com 12 produtores que atuam na produção e comercialização de uvas e vinhos. O segundo grupo é constituído pela associação de agricultores orgânicos com 13 produtores que atuam na produção, industrialização e comercialização de produtos orgânicos. O terceiro grupo é constituído por nove associações de linhas, sendo: Associação Comunitária José Bonifácio; Associação de Moradores da Linha Água Verde; Associação de Moradores da Aliança Flor da Serra; Associação de Moradores e Amigos da Linha Itá; Associação de Moradores e Amigos da Linha São José; Associação de Moradores e Amigos da Souza Naves; Associação de Produtores da Linha Sanga Funda; Associação de Pequenos Produtores da Linha Guaçu e Associação de Pequenos Produtores da Linha São João, as quais congregam no total 329 produtores rurais que atuam em atividades relacionadas à agropecuária e à agroindustrialização. A escolha destas associações deveu-se pela relevância regional, tanto por sua constituição estabelecida pela grande maioria dos produtores da região quanto por sua produção.

As fontes de dados foram primárias e secundárias. Os dados secundários foram obtidos de estatutos e relatórios das associações; e os dados primários obtidos por meio de entrevistas semiestruturadas com os associados, seus presidentes e dirigentes, além de observação não participante.

Os dados obtidos por meio de entrevistas foram classificados da seguinte forma:

- Na Associação de Produtores de Uvas e Vinhos (Apuvitis) foram feitas entrevistas com quatro sócios, um presidente e três dirigentes; 
v Na Associação dos Agricultores Orgânicos de Quatro Pontes (AAOQP) foram feitas entrevistas com dois sócios, um presidente e um dirigente; e

v Na Associação de Linhas foram feitas entrevistas com 18 sócios, nove presidentes e um dirigente.

Cada entrevista teve a duração de 50 a 60 minutos e o número de entrevistas foi definido por meio de critério de saturação dos dados.

Para o tratamento e análise dos dados qualitativos foi utilizada a análise de conteúdo e para a análise dos dados, a tabulação em categorias. Para análise dos documentos coletados foi utilizada a técnica de análise documental. A triangulação dos dados foi realizada com a utilização dos dados das entrevistas, das observações e dos documentos das associações; eles auxiliaram fundamentalmente para o desenvolvimento da análise e, principalmente, na confirmação e na credibilidade dos dados. As entrevistas gravadas foram transcritas e submetidas, juntamente com os outros documentos, à técnica de análise qualitativa de conteúdo.

\section{Apresentação e análise dos resultados}

\subsection{Estratégias de competição e colaboração das perspectivas de produtos e mercados, existentes nas associações de produtores rurais de Quatro Pontes (PR)}

Nesta investigação, para identificar as estratégias de competição observa-se como a pequena propriedade rural associada compete por meio da estratégia de diferenciação ou custo em um determinado nicho de mercado, participando como fornecedor de uma grande rede topdown; ou participando de uma rede de empresas flexíveis.

Para identificar as estratégias de colaboração observa-se como a pequena propriedade rural coopera para obter habilidades complementares, acesso a recursos, acesso a novos mercados, sinergia mútua e aprendizado.

\subsubsection{Estratégias de competição e colaboração existentes na Apuvitis}

A Associação de Produtores de Uvas e Vinhos produz uvas e vinhos com a marca Apuvitis, produtos que são comercializados individualmente pelos sócios em supermercados e feiras da cidade de Quatro Pontes e de cidades vizinhas. 
Os produtos da Apuvitis diferenciam-se das uvas e vinhos de marcas tradicionais em função de serem produzidos por uma associação de produtores rurais, que foi constituída especificamente para este fim e que recebe incentivos públicos e orientação técnica da Emater em todas as etapas do ciclo produtivo.

A uva produzida pelos produtores da associação se diferencia das demais existentes no mercado em função do bom aspecto visual, do tamanho superior do cacho e da época de maturação. Pelo fato de a uva ser produzida e comercializada na mesma região, o produto não sofre danos no transporte, o que lhe confere um excelente aspecto visual. As uvas produzidas pelos produtores da Apuvitis são das variedades vênus, niágara branca, niágara rosada, moscatéu, violeta, isabel precoce, bordô, concorde, poloski e búfalo, que possuem tamanhos de cachos superiores e amadurecem na época da entressafra, quando há falta de produto no mercado. Os vinhos da Apuvitis são produtos artesanais e são produzidos a partir das uvas dos produtores da associação e de outras localidades como sul do Paraná, Santa Catarina e Rio Grande do Sul. A Apuvitis possui os vinhos de mesa: tinto seco, branco seco e branco seco aromático. A produção de uvas e vinhos da Apuvitis não atende à grande demanda do mercado local.

Embora a Apuvitis defina o preço a ser cobrado pelo quilo da uva e pelo litro de vinho, os associados individualmente alteram os preços de acordo com o preço sugerido pelo mercado, com base no preço praticado pelos distribuidores. A questão da comercialização individual das uvas e do vinho é criticada pelo Dirigente 1 e pelo Dirigente 2. Segundo eles, essa prática gera competição entre os associados, o que pode culminar na desunião do grupo. Para ambos, a comercialização deveria ser feita de maneira centralizada pela própria Associação. O Dirigente 2 comenta que a Apuvitis é formadora de preço. Entretanto, como a comercialização é individual, os produtores não conseguem impor seu preço ao mercado e passam à condição de tomador de preços.

Observa-se que os produtores competem no mercado por meio da Apuvitis. Esse tipo de organização adota como estratégia competitiva a flexibilidade/custo participando de uma rede de empresas flexíveis, descrita por Casarotto Filho e Pires (2001). Segundo estes autores, nas funções produtivas, organizações pequenas normalmente são mais flexíveis e ágeis comparadas a grandes organizações. Se essas pequenas organizações podem agregar vantagens de grandes organizações, em função de logística, marca ou tecnologia, elas têm grandes chances de competição.

Neste sentido, os associados da Apuvitis têm flexibilidade e agilidade nas funções produtivas, bem como agregam vantagens por meio da: (1) logística, pois se localizam perto do mercado consumidor; (2) pela marca Apuvitis, 
que é sinônimo de qualidade; e com a (3) tecnologia, através da fabricação das uvas e dos vinhos na entressafra.

Entretanto, é possível observar que há competição individual entre os associados na hora da comercialização, quando os associados individualmente alteram os preços da uva e do vinho de acordo com o preço sugerido pelo mercado, com base no preço praticado pelos distribuidores.

Constatou-se que os associados da Apuvitis cooperam no sentido de obter: (1) habilidades complementares, através de assistência técnica, visitas técnicas, trocas de informações entre produtores, dias de campo, encontros de produtores de uva e vinho (2) acesso a recursos, como tecnologias, investimentos públicos, investimentos dos sócios e financiamentos; (3) acesso a novos mercados, por meio da marca Apuvitis; (4) sinergia mútua, com a obtenção de descontos e melhores preços mediante a compra conjunta de equipamentos e insumos para a cultura da uva e para a elaboração do vinho e compra conjunta de uvas para fabricação de vinhos; e (5) aprendizado, por meio de técnicas de produção de uvas e vinhos no sentido de melhorar a qualidade destes produtos.

Observa-se a existência de estratégia de competição e cooperação entre os produtores da Apuvitis, entretanto, predomina o comportamento colaborativo entre os associados da associação. A competição existente diz respeito a uma certa imposição de mercado, onde o produtor possui o livro arbítrio de tomar preços. Entretanto, as suas ações são restritas nesse sentido pela incapacidade de escala individual dos produtores que tem adotado essa iniciativa. Dessa forma, nesta Associação a colaboração é alta e a competição baixa.

\subsubsection{Estratégias de competição e colaboração existentes na AAOQP}

Atualmente a AAOQP produz diversos produtos in natura e agroindustrializados artesanalmente com a marca da AAOQP, que possuem a certificação participativa e são comercializados individual e/ou coletivamente pelos associados. Os produtos da AAOQP diferenciam-se das marcas tradicionais em função de tratar-se de produtos orgânicos que são produzidos por uma associação de produtores rurais, que foi constituída especificamente para este fim e que recebe incentivos públicos e orientação técnica da Emater, do Centro de Apoio ao Pequeno Agricultor (Capa) em todas as etapas do ciclo produtivo.

Os produtos in natura produzidos pelos produtores da AAOQP se diferenciam dos demais existentes no mercado em função do bom aspecto visual, que se deve ao fato de os produtos serem produzidos nas propriedades 
dos associados e, logo após, comercializados individualmente pelos mesmos a consumidores finais nas propriedades rurais, nos supermercados ou na feira do produtor orgânico de Quatro Pontes, que é realizada uma vez por semana. Os produtos in natura dos associados da AAOQP são leite, frutas e verduras.

Os produtos agroindustrializados produzidos pelos associados da AAOQP são produtos artesanais elaborados a partir de produtos produzidos nas propriedades dos associados ou de matéria-prima de outras localidades, comprada por um grupo de quatro associados da AAOQP. Os produtos agroindustrializados produzidos pelos associados da AAOQP são nata, queijos, frangos, geleias, vinhos, sucos, licores, cachaça, vinagre, doces, compotas, conservas e produtos de panificação, que são comercializados em supermercados e feiras do produtor, da cidade de Quatro Pontes e de cidades vizinhas, e a consumidores finais nas propriedades rurais. Todos os produtos possuem a marca da própria associação.

A produção de produtos in natura e agroindustrializados dos associados da AAOQP não atende à grande demanda do mercado regional.

Enquanto cada associado da AAOQP é responsável por plantio, manejo e colheita de seus produtos na propriedade, a agroindustrialização artesanal da produção é feita individualmente, pelos associados nas suas propriedades ou em conjunto, por quatro associados na propriedade do associado 6 , local no qual está sendo construída a agroindústria orgânica. É uma prática comum do grupo de quatro associados efetuar a produção individual e a industrialização e comercialização coletiva de produtos orgânicos, bem como a compra da matéria-prima e a industrialização e comercialização coletiva de produtos orgânicos.

O preço cobrado pelos produtos agroindustrializados é definido pelos associados conforme o processo de agroindustrialização. Se a agroindustrialização for individual, o preço é definido individualmente e a comercialização é individual. Se a agroindustrialização for coletiva, o preço é definido coletivamente e a comercialização é coletiva. Quando a AAOQP participa de feiras e/ou eventos fora do município, um associado representa a AAOQP e se encarrega de levar e vender os produtos dos demais associados.

Existe divergência sobre a agroindustrialização entre os associados. Enquanto alguns unem esforços em torno da agroindustrialização conjunta, outros defendem a agroindústria familiar e optam pela agroindustrialização individual. A agroindustrialização e a comercialização individual dos associados da AAOQP é condenada pelo Dirigente 1. Segundo ele, esta prática prejudica a união do grupo e dificulta que os produtos da marca da AAOQP tenham um padrão de qualidade. O Dirigente 1 alerta sobre a necessidade de mudança a 
partir do aumento da produção e do início das atividades da agroindústria. Para ele, a agroindustrialização e comercialização devem ser centralizadas.

Embora a aceitação dos produtos da AAOQP seja satisfatória para os produtores, a entrada dos produtos no mercado regional é dificultada. A venda individual pelos associados, a falta de espaço físico adequado para agroindustrialização e, consequentemente, a falta de registro do produto dificultam a entrada dos produtos no mercado regional e prejudicam a competitividade dos produtos da AAOQP.

Observa-se que os associados da AAOQP competem no mercado individual e coletivamente por meio da AAOQP. Esse tipo de configuração organizacional adota como estratégia competitiva a flexibilidade/custo participando de uma rede de empresas flexíveis.

Neste sentido, os associados da AAOQP têm flexibilidade e agilidade nas funções produtivas, bem como agregam vantagens através da: (1) logística, pois se localizam perto do mercado consumidor; (2) pela marca da AAOQP, que tem grande aceitação no mercado; e com a (3) tecnologia, através da fabricação de produtos orgânicos in natura e agroindustrializados.

Entretanto, é possível observar que há competição individual e coletiva entre associados em relação a produtos e mercados. Os mesmos produtos, com a mesma marca, são produzidos, agroindustrializados e comercializados no mesmo mercado com preços distintos.

Constatou-se que os associados da AAOQP cooperam no sentido de obter: (1) habilidades complementares, através do desenvolvimento de parcerias com entidades públicas e privadas, convênios, desenvolvimento de um campo experimental em fruticultura, assistência técnica, visitas a propriedades, trocas de informações entre produtores, participação em palestras e eventos sobre agricultura orgânica; (2) acesso a recursos, como tecnologias, investimentos e apoio público, investimentos dos sócios e financiamentos; (3) acesso a novos mercados, por meio de compra conjunta e venda individual ou coletiva através da marca da AAOQP; (4) buscando sinergia mútua, obtida pela certificação participativa concedida a todos os associados da AAOQP e pela obtenção de descontos por meio das compras conjuntas e de melhores preços através da agroindustrialização e vendas conjuntas realizadas por um grupo de quatro associados da AAOQP; e (5) aprendizado, mediante técnicas para a produção de orgânicos no sentido de melhorar a qualidade destes produtos.

Observa-se a existência de estratégia de competição e cooperação entre os produtores da AAOQP; entretanto, predomina o comportamento colaborativo entre os associados da associação. Embora a competição seja em relação a produtos e mercados, constata-se que nesta associação a colaboração é alta e a competição é baixa. 


\subsubsection{Estratégias de competição e colaboração existentes nas associações de linhas}

Os produtores das associações das linhas efetuam diversificação produtiva em suas propriedades e atuam em atividades relacionadas com a agropecuária e a agroindustrialização. Os associados das linhas efetuam o plantio, o manejo e a colheita de seus produtos em suas propriedades.

Os produtos in natura produzidos pelos associados das linhas são produtos agropecuários padronizados que não se diferenciam dos demais existentes no mercado. No geral são grãos (soja, milho, trigo), peixes, suínos, frangos, bovinos, leite e feno. Os grãos são colhidos nas propriedades dos produtores e parte da produção, principalmente do milho, é utilizada para fabricação e ração para o consumo animal, sendo o restante depositado em armazéns de empresas cooperativas e empresas agroindustriais, onde permanece até a fixação por parte do produtor. A produção de carnes se desenvolve geralmente no sistema de integração ou parceria com empresas cooperativas ou agroindústrias, sendo a produção entregue por lotes e o pagamento definido conforme contrato feito entre as partes, o qual considera o coeficiente de conversão alimentar. O leite é entregue diariamente a empresas cooperativas e agroindustriais, que efetuam o pagamento quinzenal ou mensal ao produtor, e o preço varia de acordo com a empresa e com a qualidade e a quantidade de leite entregue. O feno é utilizado para alimentação animal, sendo o restante comercializado individualmente para fazendeiros do sudoeste. Os produtos in natura são comercializados para cooperativas e agroindústrias da região oeste, com exceção do feno que é comercializado a fazendeiros da região sudoeste. Esses produtores possuem uma situação comercial muito incômoda por depender de intermediários; quando compram seus insumos, máquinas e equipamentos, perguntam: "quanto custa?", e quando vendem seus produtos, perguntam: "quanto pagam?" ou "qual o preço do dia?".

Os produtos industrializados produzidos pelos associados das linhas são produtos artesanais elaborados a partir dos produtos produzidos nas propriedades dos associados, com exceção das uvas que são compradas de outras localidades. Os produtos são: nata pasteurizada, vinho colonial, embutido defumado, compotas, geleias, conservas e frango diferenciado. São produtos rotulados que possuem a marca do próprio produtor. Os produtos agroindustrializados são comercializados em supermercados da cidade de Quatro Pontes e cidades vizinhas, nas feiras do produtor realizadas semanalmente em Quatro Pontes e a consumidores finais que efetuam a compra nas propriedades rurais. A situação comercial destes produtores é mais confortável porque 
eles conseguem produzir seus produtos na propriedade e levá-los ao mercado, eliminando a figura do intermediário.

A estratégia de integração mais usual utilizada pelos associados das linhas refere-se ao arranjo das atividades agropecuárias, de modo que cada uma delas auxilie e possa ou ser auxiliada por outra. Esta estratégia produtiva visa racionalizar a produção agropecuária, de forma que maximize a utilização dos recursos disponíveis e minimize custos de produção. É o caso da maioria dos associados das linhas que atuam em duas ou mais atividades que se complementam e que produzem produtos in natura que são comercializados individual ou coletivamente. Em termos de cadeia vertical de produção, esse tipo de configuração organizacional geralmente adota como estratégia competitiva a liderança de custo, participado como fornecedor de cooperativas ou agroindústrias. Nesse caso, conforme salienta Mintzberg (2006), no que tange ao comportamento da cadeia produtiva, quando há proximidade com o início dos processos produtivos a orientação é para custos; nas etapas de industrialização, a principal preocupação é com os processos de produção e sua tecnologia; próximo do mercado sua principal preocupação é com seu atendimento e distribuição.

Outra estratégia de integração utilizada por associados das linhas refere-se a realizar em uma única propriedade todas as etapas de produção, industrialização e venda de determinado produto, ou conjunto de produtos. Essa estratégia produtiva visa criar alternativas de mercado e obter todas as vantagens da agroindustrialização, ou seja, ampliar os domínios sobre os processos que agregam valor. É o caso dos associados da Associação de Moradores da Aliança Flor da Serra, onde um associado possui uma granja de rebanho leiteiro na qual produz leite e extrai a nata pasteurizada colonial, que é comercializada individualmente pelo associado em supermercados da cidade; e de outro associado da mesma associação que possui uma vinícola onde produz, industrializa e comercializa individualmente os vinhos; ou ainda dos associados da Associação de Pequenos Produtores da Linha São João, onde alguns associados possuem granjas de suínos na qual produzem carne e processam em embutido defumado, que é comercializado individualmente na feira do produtor rural; e de outros associados da mesma associação que produzem em sua propriedade leite, frutas e verduras e as processam em derivados do leite, compotas, geleias e conservas, as quais também são comercializadas individualmente na feira do produtor rural. Nesses casos, o tipo de configuração organizacional adotado constitui como estratégia competitiva de diferenciação de produto associado a um nicho de mercado, onde a ênfase é custo; processos 
de produção e tecnologia; e atendimento e distribuição, pelo fato de o associado ser o coordenador da cadeia produtiva.

Uma estratégia de integração menos usual utilizada pelos associados das linhas refere-se a realizar em propriedades distintas as etapas de produção, industrialização e efetuar a comercialização coletivamente. Essa estratégia produtiva também visa criar alternativas de mercado e obter todas as vantagens da agroindustrialização, ou seja, ampliar os domínios sobre os processos que agregam valor. É o caso dos associados da Associação de Moradores da Aliança Flor da Serra, onde dois associados produzem e industrializam individualmente frangos diferenciados, os quais são comercializados coletivamente. A venda coletiva visa fornecer uma quantidade de produtos semanalmente ao supermercado. Esse tipo de configuração organizacional adota como estratégia competitiva a flexibilidade/custo participando de uma rede de empresas flexíveis, onde a ênfase é custo; processos de produção e tecnologia; e atendimento e distribuição, pelo fato de o associado ser o coordenador da cadeia produtiva.

Independente da adoção de uma estratégia competitiva à liderança de custo, participado como fornecedor de cooperativas ou agroindústrias, uma estratégia competitiva de diferenciação de produto associado a um nicho de mercado ou uma estratégia competitiva de flexibilidade/custo participando de uma rede de empresas flexíveis, esses associados também participam de atividades coletivas, em redes constituídas por participantes onde também se beneficiam por meio do uso de máquinas e equipamentos fornecidos pela associação, que apoia suas estratégias e seus resultados individuais.

Segundo os depoimentos de associados, presidentes e dirigentes, os associados efetuam a diversificação produtiva nas unidades produtivas em atividades relacionadas à agropecuária e à agroindustrialização. Desta forma, pode se verificar que alguns associados das associações de linhas competem no mercado individual ou coletivamente com uma, duas ou com as três estratégias competitivas propostas por Casarotto Filho e Pires (2001), ou seja, liderança de custo, participado como fornecedor de uma grande rede topdown, diferenciação de produto associado a um nicho de mercado e flexibilidade/custo participando de uma rede de empresas flexíveis.

Embora não haja competição entre os associados no que tange a produtos e mercados, a competição ocorre entre as associações e entre os associados para o acesso aos recursos. A competição entre as associações ocorre quando da decisão do repasse dos recursos. A decisão sobre a associação contemplada no repasse dos recursos é definida pelo responsável da Secretaria de Desenvolvimento Econômico que congrega as pastas Agricultura, Indústria e Comércio, 
Meio Ambiente e Turismo e o Conselho Agropecuário do Município de Quatro Pontes, entidade onde participam os presidentes de associações. A competição entre associados ocorre no uso dos recursos das associações.

Apesar de cada recurso das associações possuir normatização que regulamenta o uso de cada um dos equipamentos, alguns associados infringem o regimento em benefício próprio ou se beneficiam dos recursos, pois possuem máquinas e equipamentos próprios.

Constatou-se que os associados das linhas cooperam no sentido de obter: (1) habilidades complementares, através do desenvolvimento de parcerias e convênios com entidades públicas e privadas, assistência técnica, trocas de informações entre produtores e participação em cursos, palestras e dias de campo; (2) acesso a recursos, como tecnologias, investimentos e apoio público, investimentos dos sócios e financiamentos; (3) acesso a novos mercados, por meio da comercialização em conjunto realizada por duas famílias como forma de viabilizar a produção em escala e obter vantagens em termos de mercado e preço; (4) sinergia mútua, obtida por meio de menores preços nas compras conjuntas de equipamentos e de melhores preços através de vendas conjuntas, da cooperação dos associados no que tange a disponibilidade de mão de obra e maquinário para executar fenação ou silagem, e da troca de serviços realizada entre os sócios em épocas específicas como no plantio; (5) aprendizado, relacionado a técnicas de produção no sentido de melhorar a qualidade de vida e a qualidade e produtividade da produção agropecuária e agroindustrial.

Observa-se a existência de competição e cooperação entre associados das associações de linhas. A competição existente está restrita ao acesso aos recursos. Portanto, predomina o comportamento colaborativo entre os associados da associação.

\subsection{Resultados individuais e coletivos obtidos pelos produtores participantes das associações de produtores rurais de Quatro Pontes (PR)}

Para identificar os resultados individuais, são observados as perspectivas de desempenho e os resultados individuais dos associados das associações pesquisadas.

Para identificar os resultados coletivos, são observados as perspectivas de desempenho e os resultados coletivos dos associados das associações pesquisadas. 


\subsubsection{Resultados individuais e coletivos dos produtores da Apuvitis}

As perspectivas de desempenho individual dos associados da Apuvitis eram melhorar a geração de renda. Segundo os associados, presidentes e dirigentes, a produção de uvas proporciona um resultado financeiro superior se comparado com outras atividades desenvolvidas na região. Os dirigentes destacam que a uva pode propiciar ao produtor uma renda 24 vezes maior que a soja. Os resultados individuais dos associados da Apuvitis demonstram efetivamente que a produção e a comercialização de uvas geram emprego e renda na pequena propriedade rural com margens de lucratividade maiores em comparação à produção de soja.

As perspectivas de desempenho coletivo dos associados da Apuvitis eram possuir uma segurança através da comercialização dos vinhos e melhorar os resultados individuais. Os associados destacam a construção da vinícola, que propiciou a fabricação dos vinhos. Os dirigentes destacam que o vinho pode propiciar ao produtor uma renda 27 vezes maior que a soja. No I Concurso de Vinhos da Região Oeste, realizado em setembro de 2008, os vinhos da categoria colonial da Apuvitis receberam três premiações; 1ำ lugar: Branco Seco Aromático, $2^{\circ}$ lugar: Tinto Seco e $2^{\circ}$ lugar Branco Seco. Os resultados coletivos dos associados da Apuvitis demonstram efetivamente que a produção e a comercialização de vinhos de qualidade geram segurança, emprego e renda na pequena propriedade rural com margens de lucratividade maiores em comparação às da produção de soja e da própria uva. Além disso, através dos vinhos os associados divulgam o trabalho da Associação, o município, os produtores e os produtos.

\subsubsection{Resultados individuais e coletivos dos produtores da AAOQP}

As perspectivas de desempenho individual dos associados da AAOQP eram de aumentar a qualidade de vida, através do consumo de produtos orgânicos, e aumentar a renda por meio da produção, industrialização e comercialização de produtos orgânicos. Os resultados individuais dos associados da AAOQP demonstram efetivamente que a produção de orgânicos proporciona uma melhoria na qualidade de vida dos associados e um resultado financeiro superior, se comparado com outras atividades agropecuárias desenvolvidas na região. Além disso, os associados da AAOQP alcançaram a sustentabilidade na atividade através de uma regularidade de renda ao longo do ano.

As perspectivas de desempenho coletivo dos associados na AAOQP eram conseguir um local adequado para efetuar a agroindustrialização. Os resulta- 
dos coletivos dos associados na AAOQP demonstram efetivamente que eles conquistaram coletivamente a construção da agroindústria e contribuem para a preservação do meio ambiente, geração de renda, empregos e impostos.

\subsubsection{Resultados individuais e coletivos dos produtores das associações de linhas}

As perspectivas de desempenho individual dos associados das linhas eram obter benefícios em termos econômicos, sociais e informacionais por meio das associações de linhas. Os resultados individuais dos associados das linhas demonstram efetivamente que todos os associados através das associações de linhas obtiveram e continuam a obter benefícios em termos econômicos, sociais e informacionais.

As perspectivas de desempenho coletivo dos associados das linhas era a manutenção e sustentabilidade da pequena propriedade rural. Os resultados coletivos dos associados das linhas demonstram efetivamente que os associados das linhas se mantêm e têm sustentabilidade na pequena propriedade rural, bem como contribuem para a geração de empregos no campo, renda para a sociedade e impostos à Prefeitura Municipal.

\subsection{Estratégias de competição e de colaboração e os resultados individuais e coletivos dos produtores}

Neste item procurou-se verificar de que forma as estratégias de competição e de colaboração das associações de produtores rurais de Quatro Pontes (PR) contribuem para a obtenção de resultados individuais e coletivos de seus participantes.

\subsubsection{Estratégias de competição e de colaboração e os resultados individuais e coletivos dos produtores da Apuvitis}

A maioria dos associados da Apuvitis atua na produção e na comercialização de uvas e vinhos. Esses associados comercializam grande parte da uva in natura e disponibilizam parte para a produção de vinhos e/ou compram em conjunto, através da Apuvitis, uvas de outras regiões para transformar em vinhos. Estes fatos evidenciam que os associados aproveitam duas oportunidades de 
melhorar sua renda: os associados vendem a uva para consumo in natura por preços elevados e compram uva por um preço mais baixo para transformação em vinhos, o que lhes permite atingir os resultados individuais, bem como contribuir para melhorar os resultados coletivos e objetivos da Apuvitis.

Entretanto, quatro associados da Apuvitis atuam somente na produção e na comercialização de uvas in natura. Esses associados também não disponibilizam uvas para a fabricação de vinhos e não compram uvas em conjunto com os demais associados da Apuvitis para produção e comercialização de vinhos. $\mathrm{O}$ fato evidencia que esses associados comprometem, de certa forma, seus resultados individuais em função de concentrar seus esforços na produção e comercialização de uvas in natura, e deixam de obter receita adicional promovida pela associação através da venda de vinhos, bem como comprometem os resultados coletivos da Apuvitis, que opera com ociosidade em sua capacidade industrial.

A produção e a comercialização de uva individualmente são restritas em termos de mercado e preço, pois limitam a capacidade competitiva em torno da uva. A produção e a comercialização de uvas geram emprego e renda na pequena propriedade rural com margens de lucratividade maior em comparação com a produção de soja.

A produção e a comercialização de uvas individualmente consorciada com a produção coletiva e a comercialização individual de vinhos aumentam a capacidade competitiva, porém a comercialização individual de uvas e vinhos exige investimentos e custos individuais ao longo do ano. A construção da vinícola permite a produção e a comercialização de vinhos de qualidade, o que gera segurança, emprego e renda na pequena propriedade rural com margens de lucratividade maior em comparação com a produção de soja e a própria uva. Além disso, através dos vinhos os associados divulgam o trabalho da associação, o município, os produtores e os produtos.

\subsubsection{Estratégias de competição e de colaboração e os resultados individuais e coletivos dos produtores participantes da AAOQP}

A maioria dos associados da AAOQP efetua a produção, industrialização e comercialização individual de produtos orgânicos que é restrita em termos de mercado e preço, pois os associados deixam de obter ganhos adicionais por meio da obtenção de descontos via compras conjuntas e de melhores preços mediante a agroindustrialização e vendas conjuntas. A produção, industrialização e comercialização individual de produtos orgânicos geram impostos, 
emprego e renda na pequena propriedade rural, com margens de lucratividade maiores em comparação com a produção agropecuária, o que permite ao associado alcançar individualmente a sustentabilidade na atividade através de uma regularidade de renda ao longo do ano.

Quatro associados da AAOQP efetuam a produção individual e a industrialização e comercialização coletiva de produtos orgânicos; bem como a compra, industrialização e comercialização coletiva de produtos orgânicos, o que melhora a capacidade competitiva dos associados, otimiza o uso dos recursos materiais, financeiros, humanos, mercadológicos e administrativos e viabiliza a produção em escala, permitindo obter vantagens em termos de mercado e preço. Estes associados obtêm ganhos adicionais através de descontos nas compras conjuntas e de melhores preços através da agroindustrialização e de vendas conjuntas. A produção individual e a industrialização e comercialização coletiva de produtos orgânicos, bem como a compra, industrialização e comercialização coletiva de produtos orgânicos geram impostos, emprego e renda na pequena propriedade rural, com margens de lucratividade maiores em comparação com a produção agropecuária, o que permite aos associados alcançar coletivamente a sustentabilidade na atividade através de uma regularidade de renda ao longo do ano. Além disso, através da associação, os associados conquistaram coletivamente a construção da agroindústria e contribuem para a preservação do meio ambiente, geração de renda, empregos e impostos.

\subsubsection{Estratégias de competição e de colaboração e os resultados individuais e coletivos dos produtores das associações de linhas}

Quando os associados das linhas participam como fornecedor de uma grande rede topdown, o fornecedor (associado) é altamente dependente das estratégias da empresa-mãe (cooperativa ou agroindústria) e tem pouca ou nenhuma flexibilidade ou poder de influência nos destinos da rede. Isto pode ser verificado nos associados que atuam nas atividades agropecuárias e comercializam seus produtos individual e coletivamente, sendo os associados tomadores de preços. Entretanto o arranjo das atividades agropecuárias, de modo que cada uma delas auxilie e possa ser auxiliada pela outra, racionaliza a produção agropecuária, de forma a maximizar a utilização dos recursos disponíveis e minimizar os custos de produção, o que permite a sustentabilidade na atividade.

Os associados das linhas que efetuam a diferenciação de produto associado a um nicho de mercado agregam valor aos produtos, de modo que este 
supere o preço pago pelo consumidor. Isto pode ser verificado nos associados que atuam nas atividades agroindustriais da nata pasteurizada, do vinho colonial, do embutido defumado, de derivados do leite, das compotas, geleias e conservas, que comercializam seus produtos individualmente, sendo os associados formadores de preços. Estes associados criar alternativas de mercado e obtêm todas as vantagens da agroindustrialização, ou seja, ampliam os domínios sobre os processos que agregam valor.

Quando os associados das linhas adotam a estratégia de flexibilidade/ custos, participando de uma rede de empresas flexíveis, obtêm mais flexibilidade e agilidade, bem como agregam vantagens por meio da: (1) logística, pois se localizam perto do mercado consumidor e com a (2) tecnologia, através da fabricação de produtos agroindustrializados. Isto pode ser verificado nos associados que atuam na produção e agroindustrialização individual de frangos diferenciados os quais não comercializam coletivamente, sendo os associados os formadores de preços. Esses associados criam alternativas de mercado e obtêm todas as vantagens da agroindustrialização, ou seja, ampliam os domínios sobre os processos que agregam valor.

Independente da(s) estratégia(s) competitiva(s) utilizada(s) pelos associados das linhas, eles participam de uma rede constituída por participantes flexíveis, onde os benefícios econômicos, sociais e informacionais obtidos apoiam as estratégias e os resultados individuais dos associados.

\section{Considerações finais}

A Apuvitis, a AAOQP e as associações de linhas têm definição conceitual distinta da definição de associação de produtores rurais identificada pelo Ministério da Agricultura, Pecuária e Abastecimento, em Brasil (2008), e por Muenchen (1996). Para ambos, associações de produtores rurais são organizações formais que integram esforços coletivos em torno de objetivos e interesses comuns. Através deste estudo, sugere-se uma definição conceitual ampliada, como: associações de produtores rurais são entidades que agrupam produtores rurais com interesses econômicos, sociais e informacionais que atuam tanto de forma competitiva como colaborativa, o que lhes permite obter resultados individuais e coletivos. Portanto, associativismo rural constitui-se em uma forma de configuração de rede que possibilita às pessoas e seus empreendimentos adotar estratégias competitivas e colaborativas visando obter resultados individuais e coletivos. 
Desta forma, existe nas associações de produtores rurais pesquisadas a coopetição, ou seja, um comportamento simultaneamente cooperativo e competitivo (Bengtsson e Kock, 1999; Tsai, 2002; Luo, Slotegraaf e Pan, 2006; Chien e Peng, 2005), com resultados individuais e coletivos para os produtores participantes.

Nos três estudos de caso, a colaboração é alta e a competição é baixa. Este resultado pode estar relacionado às características de governança das associações ou ao fato de a colaboração mostrar-se um comportamento socialmente aceitável em relação à competição. Verifica-se que independente da predominância de um comportamento colaborativo nos relacionamentos interorganizacionais, os associados utilizam estratégias competitivas e colaborativas simultaneamente, as quais influenciam os resultados individuais e coletivos nas associações. Dessa forma, a variável interveniente relacionamento interorganizacional tem efeito indireto sobre os resultados e influencia a adoção de estratégias competitivas e colaborativas que, por sua vez, influenciam os resultados individuais e coletivos.

Segundo Child, Faulkner e Tallman (2005), a cooperação pode existir juntamente com a competição, mas não sem tensões e resultados variáveis. Para os autores, onde a colaboração é alta e a competição é baixa, haverá fortes pressões para que ocorra a fusão dos parceiros, ou para um adquirir o outro. Na Apuvitis, as pressões exercidas partem das entidades envolvidas e, essas, atuam no sentido que sempre a comercialização das uvas e do vinho seja conduzida por intermédio da Associação, ampliando sua capacidade de torná-la formadora efetiva de preços. Na AAOQP, as pressões exercidas partem das entidades envolvidas e buscam a agroindustrialização e a comercialização conduzida pela associação, visando padronizar a qualidade dos produtos e também torná-la efetivamente formadora de preços. Nas associações de linhas, as pressões exercidas partem de todos os envolvidos e buscam o bomsenso no direcionamento e no uso dos recursos coletivizados, de modo que sejam contemplados e priorizados as associações e os associados que possuem maior necessidade no uso destes recursos.

Na Apuvitis a competição existente diz respeito à imposição do mercado, onde o produtor possui o livre-arbítrio de tomar preços. Entretanto, suas ações são restritas pela incapacidade de escala individual dos produtores que têm adotado essa iniciativa. Na AAOQP a competição é relacionada a produtos e mercados e acontece de forma individual e coletiva. Nas associações de linhas a competição existente está restrita ao uso dos recursos da associação. Nos três casos estudados, a colaboração é observada no sentido de como o 
associado coopera para obter habilidades complementares, acesso a recursos; acesso a novos mercados, sinergia mútua e aprendizado.

De maneira geral, observa-se que, enquanto as estratégias de competição se diferenciam e acontecem de forma individual e coletiva, as estratégias de colaboração são similares em todas as associações de produtores pesquisadas e acontecem de forma coletiva. Este fato pode indicar que os associados priorizam a obtenção de resultados individuais em detrimento dos resultados coletivos.

A organização do segmento agropecuário da Apuvitis, da AAOQP e das associações de linhas é distinta da organização do segmento agropecuário definida por Araújo (2003). Para Araújo (2003), o segmento agropecuário é composto por pequenos e numerosos produtores rurais, os quais estão distribuídos e distanciados em grandes espaços e têm pouca organização representativa, de modo que não têm força de formar o preço de seus produtos. Neste estudo, direcionou-se a organização do segmento agropecuário por meio de associações de produtores rurais e obtiveram-se características distintas das definidas anteriormente por Araújo (2003).

A característica típica do segmento agropecuário organizado por meio de associação de produtores rurais é a de pequenos produtores rurais, distribuídos e distanciados por pequenos espaços, com força política e representativa, de modo que, dependendo da estratégia adotada, têm força suficiente para agroindustrializar, romper as barreiras comerciais, inserir-se em um contexto competitivo, formar o preço de seus próprios produtos e ofertá-los ao mercado.

A organização por meio de associações de produtores rurais permite aos associados efetuar a agregação de valor ideal, eliminar a figura do intermediário nos segmentos "antes da porteira" e "depois da porteira", bem como romper a situação de dependência e submissão com o segmento depois da porteira, que tanto penaliza o produtor e que gera sequelas sociais danosas para a sociedade rural e urbana. Para Araújo (2003), a agregação de valor ideal é aquela que ocorre em condições socialmente justas, ou seja, quando há distribuição de renda ao longo de toda a cadeia produtiva, em cada etapa da produção, da agroindustrialização e da comercialização, com intuito de beneficiar o consumidor.

Outra observação dos dados sugere que o associativismo rural permite melhorar a integração dos segmentos do agronegócio denominados "antes da porteira", "dentro da porteira" e "após a porteira", pelo fato de envolver ações relacionadas à tecnologia, capacitação, organização, produção, transformação e comercialização; ou até mesmo a fusão dos segmentos "dentro da porteira" e "após a porteira", uma vez que a literatura prega que a "agroindustrialização 
verticalizada dentro das fazendas não faz parte do segmento do agronegócio dentro da porteira, mas depois da porteira" (Araújo, 2003:47).

As associações de produtores rurais são estratégias formuladas como resposta aos desafios enfrentados pelos pequenos produtores rurais. Assim, as associações são um meio para um fim, sendo formadas inicialmente com vistas ao relacionamento colaborativo de longo prazo. Quando as associações de produtores rurais são ativas, os associados percebem os benefícios da colaboração não previstos inicialmente, avaliando-os positivamente, como é o caso das inovações ali possibilitadas pelo acesso ao conhecimento e à tecnologia superior.

Assim, os associados podem usufruir das associações como um meio de melhoria da competitividade e da obtenção de habilidades complementares, acesso a novos mercados, oportunidades para sinergia mútua e aprendizado. A estrutura de relacionamentos que envolvem as associações de produtores rurais é utilizada como instrumento de repasse de recursos oficiais que promovem benefícios econômicos, sociais e informacionais aos associados, viabilizando, mantendo e modernizando a base produtiva.

Por fim, os resultados individuais e coletivos obtidos pelos produtores participantes indicam que associações de produtores rurais desempenham um papel fundamental na manutenção e na sustentabilidade dos pequenos produtores rurais e podem contribuir para a melhoria da educação, da renda e da qualidade de vida de sua comunidade.

\section{Referências}

ABRANTES, José. Associativismo e cooperativismo: como a união de pequenos empreendedores pode gerar emprego e renda no Brasil. Rio de Janeiro: Interciência, 2004.

ALDRICH, H.E. Organizations and environments. New Jersey: Prentice-Hall, 1979.

AMATO NETO, João. Redes de cooperação produtiva e clusters regionais: oportunidade para as pequenas e médias empresas. São Paulo: Atlas, 2000.

ARAÚJO, Massilon J. Fundamentos de agronegócio. São Paulo: Atlas, 2003.

AZEVEDO, J.F. Associativismo e agroecossistemas: um estudo em Nossa Senhora da Glória (SE). 107 f. Dissertação (mestrado) — Universidade Federal de Sergipe, Aracaju, 2006. 
BALESTRIN, A.; VARGAS, L.M. A dimensão estratégica das redes horizontais de PMEs: teorizações e evidências. Revista de Administração Contemporânea, Curitiba, v. 8, p. 203-227, 2004. Edição Especial.

BENGTSSON, M.; KOCK, S. Cooperation and competition in relationships between competitors in business networks. The Journal of Business \& Industrial Marketing, v. 14, n. 3, p. 178-194, 1999.

BRASIL. Ministério da Agricultura, Pecuária e Abastecimento. Associativismo. Brasília: Mapa/SDC/Denacop, 2008.

CÂNDIDO, G.A. Fatores críticos de sucesso no processo de formação, desenvolvimento e manutenção de redes interempresariais do tipo agrupamento industrial entre pequenas e médias empresas: um estudo comparativo de experiências brasileiras. $356 \mathrm{f}$. Tese (doutorado em engenharia de produção) - Universidade Federal de Santa Catarina, Florianópolis, 2001.

CARNEIRO, M.J. Política de desenvolvimento e o "Novo Rural". In: SEMINÁRIO INTERNACIONAL "O NOVO RURAL BRASILEIRO”, 1., Campinas, 1999. Anais... Campinas: IE/Unicamp, Projeto Rurbano, mar. 1999.

CASAROTTO FILHO, Nelson; PIRES, Luiz Henrique. Redes de pequenas e médias empresas e desenvolvimento local: estratégia para a conquista da competitividade global com base na experiência italiana. São Paulo: Atlas, 2001.

CASTRO, Marcos de. Relacionamentos inteorganizacionais e resultados: estudo na associação dos comerciantes de materiais de construção da região de Guarapuava — PR. 171 f. Dissertação (mestrado) — Universidade Federal do Paraná, Curitiba, 2007.

CHIEN, Ting-Hua; PENG, Tzue-Ju. Competition and cooperation intensity in a network: a case study in Taiwan Simulator Industry. Journal of American Academy of Business, v. 7, n. 2, p. 150-155, 2005.

CHILD, J.; FAULKNER, D. Strategies of co-operation: managing alliances, networks, and joint ventures. New York: Oxford University Press, 1998.

CHILD, John; FAULKNER, David; TALLMAN, Stephen. Cooperative strategy. New York: Oxford University Press, 2005.

COLLIS, D. Organizational capability as a source of profit. In: MOINGEON, B.; EDMONDSON, A. (Ed.). Organizational learning and competitive advantage. London: Sage, 1996. p. 139-163.

COSTA, Anita Aline Albuquerque; RIBEIRO, Tereza Cristina Almeida. O associativismo no meio rural brasileiro: contradições e perspectivas. In: CONGRESSO 
BRASILEIRO DE ECONOMIA E SOCIOLOGIA RURAL, 37., Foz do Iguaçu, 1999. Anais... Foz do Iguaçu, 1999.

DROUVOT, H; FENSTERSEIFER, J.E. O papel das redes de cooperação nas políticas de inovação tecnológica das pequenas e médias empresas. In: ENANPAD, Salvador, 2002. Anais... Salvador, 2002.

GANANÇA, Alexandre Ciconello. Associativismo no Brasil: características e limites para a construção de uma nova institucionalidade democrática participativa. 134 f. Dissertação (mestrado) — Universidade de Brasília, Brasília, 2006.

GERINGER, J.M.; HEBERT, L. Control and performance of international joint ventures. Journal of International Business Studies, v. 20, n. 2, p. 235-254, 1989.

GERLACH, Fábio Ravazi. Impactos do associativismo na pecuária leiteira paulista: estudo de casos. 165 f. Dissertação (mestrado) - Universidade Federal de São Carlos, São Carlos, 2004.

HALL, R. H. Organizações: estruturas, processos e resultados. São Paulo: Prentice Hall, 2004.

LEISMANN, Edison Luiz. Sustentabilidade socioeconômica das pequenas propriedades agrícolas. In: VANDERLINDE, Tarcísio; GREGORY, Valdir; DEITOS, Nilceu Jacob (Org.). Migrações e a construção do oeste do Paraná: século XXI em perspectiva. Cascavel: Coluna do Saber, 2007.

LEVIN, Michael A.; MCDONALD, Robert E. R-A theory as a post-Chicago argument for legal coopetition. Marketing Management Journal, v. 16, p. 1-12, 2006.

LUO, Xueming; SLOTEGRAAF, Rebecca J.; PAN, Xing. Cross-functional "coopetition": the simultaneous role of cooperation and competition within firms. Journal of Marketing, v. 70, n. 2, p. 67-80, 2006.

MINTZBERG., H. Distinguindo o principal negócio da empresa. In: MINTZBERG, H. et al. O processo da estratégia. 4. ed. Porto Alegre: Bookman, 2006.

MUENCHEN, José Valdemir. O planejamento e o controle da produção em associações de pequenos agricultores. 109 f. Dissertação (mestrado) — Escola Superior de Agricultura Luiz de Queiroz, Piracicaba, 1996.

PARKHE, A. Strategic alliance structuring: a game theoretic and transaction cost examination of interfirm cooperation. Academy of Management Journal, v. 36, n. 4, p. 794-829, Aug. 1993.

PFEFFER, J.; SALANCIK, G.R. The external control of organizations: a resource dependence perspective. Nova York: Harper and Row, 1978. 
PORTER, M.E. Competitive strategy: techniques for analyzing industries and competitors. New York: Free Press, 1980.

ROWLEY, Timothy J. Moving beyond dyadic ties: a network theory of stakeholder influences. The Academy of Management Review, v. 22, n. 4, p. 887-910, Oct. 1997.

SCHERMERHORN JR, J. R. Determinants of interorganizational cooperation. Academy of Management Journal, v. 18, n. 4, p. 846-856, 1975.

TSAI, Wenpin. Social structure of "coopetition" within a multiunit organization: coordination competition, and intraorganizational knowledge Sharing. Organizational Science, v. 13, n. 2, p. 179-190, 2002.

WEGNER, D.; DAHMER, L.V. Ferramenta para avaliação de desempenho em redes de empresas: uma proposta metodológica. In: SEMINÁRIO DE ADMINISTRAÇÃO FEA/USP, 7., São Paulo, 2004. Anais... São Paulo: FEA/USP, 2004. 1 CD-ROM.

YAN, A.; GRAY, B. Bargaining power, management control, and performance in United States-China joint ventures: a comparative case study. Academy of Management Journal, v. 37, n. 6, p. 1478-1517, Dec. 1994. 
Esteartigo sofreu al terações por solicitação do editor em conforme ERRATA publicada no Volume 45 Número 6 do periódico.

http: //www.scielo.br/scielo.php?script=sci_arttext\&pid=S0034-76122011000600018\&lng 